\title{
EL USO DE PLATAFORMAS SINCRÓNICAS APLICADAS A LA ENSEÑANZA DEL PERIODISMO
}

Ana Virginia Rubio-Jordán 1: Universidad a Distancia de Madrid. España anavirginia.rubio@udima.es

\section{RESUMEN}

Los sistemas sincrónicos resultan de gran utilidad en la enseñanza a distancia, ya que facilitan la interacción y la discusión en tiempo real, con lo cual se realiza un feedback de manera inmediata entre el profesor y el estudiante. El objeto de este trabajo es realizar una valoración de la utilidad de la plataforma Elluminate Live! en la realidad docente del Grado de Periodismo de la UDIMA. Entre los principales usos de esta herramienta destacamos los siguientes: tutorías on-line; habilitación de los estudiantes para la elaboración de trabajos en grupo, compartir documentos y aplicaciones; la colaboración de expertos desde cualquier parte del mundo y exposiciones en directo de los alumnos a través de la Webcam. En este estudio se detallan las experiencias y los resultados llevados a cabo con las distintas materias del Grado. Como conclusión queda demostrado que la mayoría de los estudiantes consideran Elluminate Live! una herramienta de fácil acceso y de gran utilidad, ya que curso tras curso demandan cada vez más sesiones formativas por parte de los docentes.

PALABRAS CLAVE: TICs - Proceso-enseñanza-aprendizaje - Plataforma sincrónica Entorno de aprendizaje virtual

\footnotetext{
${ }_{1}^{1}$ Autor correspondiente

Ana Virginia Rubio-Jordán: Profesora en el Departamento de Periodismo, Historia y Humanidades. Universidad a Distancia de Madrid. Madrid, España

Correo: anavirginia.rubio@udima.es
} 


\title{
THE USE OF SYNCHRONOUS PLATFORMS APPLIED TO JOURNALISM EDUCATION
}

\begin{abstract}
Synchronous systems are very useful in distance learning, and to facilitate interaction and discussion in real time, which is done immediately feedback between teacher and student. The purpose of this paper is to make an assessment of the usefulness of the platform Elluminate Live! in the reality of teaching the Journalism Degree UDIMA. Among the major uses of this tool to highlight the following: on-line tutorials, enabling students to develop group work, share documents and applications, the collaboration of experts from anywhere in the world and live presentations students via webcam. This study details the experiences and results performed with different subjects of the Degree. In conclusion it is demonstrated that most students consider Elluminate Live! an easily accessible tool and very useful, as course after course increasingly demanding training sessions by the teachers.
\end{abstract}

KEY WORDS: ICT Teaching-learning process Synchronic platform Virtual learning environment

\section{INTRODUCCIÓN}

El proceso de globalización acontecido en las últimas décadas ha traído consigo numerosos cambios en lo que respecta a la adquisición de nuevos conocimientos y habilidades. En el ámbito de la educación superior, las Tecnologías de la Información y la Comunicación (TICs) han supuesto una transformación en el proceso de enseñanza-aprendizaje. La implantación de herramientas tecnológicas como recursos pedagógicos permite que se racionalice el trabajo educativo del alumnado y del profesorado, desencadenando nuevas formas de comunicación entre ambos. Hoy día nadie duda de la importancia de incluir en los niveles educativos materias relacionadas con las nuevas tecnologías y eso se hace especialmente relevante cuando nos referimos a la enseñanza superior a distancia.

Debemos considerar que la educación es parte integrante de las nuevas tecnologías y que un número cada vez mayor de universidades en todo el mundo está exigiendo la alfabetización electrónica como uno de los requisitos en sus exámenes de acceso y graduación, por considerar que es un objetivo esencial para preparar a los futuros profesionales para la era digital en los centros de trabajo (Rosario, 2005).

Las innovaciones tecnológicas en lo referente a las TICs ha permitido el desarrollo de nuevas experiencias educativas inimaginables hasta hace tan solo unos años, como son las que permiten al alumno un mayor control sobre su propio proceso de aprendizaje. Es decir, el estudiante es el protagonista de su proceso formativo. De este modo, las TICs se encuadran dentro del Espacio Europeo de Educación Superior 
(EEES) aonae eı aıumno es sujeto actıvo ae esta nueva ensenanza. se cumpıe ae este modo el sueño de Ortega cuando afirmaba que en la construcción de la universidad había que partir del alumno y no del saber, ni del profesor (Ortega, 1982).

Las formas de interacción entre los docentes y los estudiantes pueden tener lugar de dos maneras: de forma sincrónica y asincrónica. En estas últimas destaca el uso del correo electrónico y los foros de discusión. Sin embargo, nosotros centramos nuestro trabajo en la comunicación sincrónica que se establece entre profesor y alumno o entre alumno y alumno, por considerar que mejoran la comunicación entre ambos, favorece el aprendizaje cooperativo así como la realización de trabajos grupales.

El empleo de las TICs aporta numerosas ventajas a la enseñanza superior que se materializan en una mejora de la calidad docente. Entre las principales ventajas podemos destacar la eliminación total de barreras espacio-temporales que tanto condicionaban a la enseñanza presencial. Hoy día cualquier persona puede cursar estudios dónde desee y cuándo desee con independencia del lugar donde viva o trabaje.

No debemos olvidar que para que la utilización de las TICs se lleve a cabo de forma correcta y se logre su máxima optimización, es necesario que las universidad formen a sus docentes en este campo, para que éstos puedan cambiar de actitud y se sientan a la vez más seguros, dado que su utilización significa un cambio de rol en el aula y la exigencia de cambiar sus métodos y estrategias didácticas (Castillo y Cabrerizo, 2006).

En ese sentido, la Universidad a Distancia de Madrid (UDIMA) ha realizado una apuesta sólida por la utilización de las Tecnologías de la Información y de la Comunicación en sus modelos de enseñanza, consciente del papel fundamental que juegan en la vida académica y profesional.

El Grado de Periodismo no es inmune a los cambios que se están produciendo y de ahí que disponga de un plan de estudios donde la transversalidad de las nuevas tecnologías resulta evidente en clara respuesta a las demandas que reclama la sociedad actual y el mundo profesional periodístico de hoy.

\section{DESARROLLO}

\subsection{El uso de las TICs en la enseñanza universitaria a distancia}

El grado de Periodismo de la UDIMA, debido a las particularidades que conlleva la educación a distancia, desarrolla en gran medida su acción formativa a través de la plataforma educativa Moodle, la cual permite habilitar un entorno virtual de aprendizaje para cada una de las asignaturas que facilita el desarrollo de acciones formativas. En dicho entorno virtual, es posible realizar una comunicación fluida entre el alumno y el docente, así como entre los estudiantes entre sí. 
sin empargo, Ia apuesta tecnologica por parte ae Ia UVIIVIA no se ılmita unicamente a la utilización de Moodle. Existen otras herramientas que sirven como un complemento a la enseñanza a distancia en todos los grados y también en el de Periodismo. Estas herramientas son Elluminate Live!, Second Life, así como algunas aplicaciones de Google como Google Docs y Google Sites.

Es interesante saber cómo aprenden los alumnos mediante el uso de estas herramientas pero a su vez conviene conocer la utilidad obtenida por parte del docente en su labor académica diaria. En este trabajo nos centramos en la valoración de la utilidad de la plataforma Elluminate Live! en la realidad docente del Grado de Periodismo de la UDIMA.

Elluminate Live! es un entorno de aprendizaje que permite superar las barreras que conlleva una clase presencial, ya que el alumno puede entrar en la sesión desde cualquier lugar del mundo, siempre y cuando disponga de conexión a Internet. Una de sus principales ventajas es, como veremos, que facilita la interacción y la discusión en tiempo real, con lo cual se realiza un feedback de manera inmediata entre el profesor y el alumno.

Mediante el uso de Elluminate es posible plasmar en tiempo real la enseñanza y supervisión de un profesor o tutor, ya que la comunicación es bidireccional, al ser posible intercambiar mensajes de texto a través del chat, mostrar vídeos y diapositivas en una pizarra virtual, así como cualquier otra aplicación $u$ archivo multimedia.

En nuestro país fue pionera en analizar la usabilidad de Elluminate Live! la Universidad de Valencia, ya que fue la primera universidad que presentó un proyecto piloto realizado desde mayo de 2007 a mayo de $2008^{2}$. Las conclusiones derivadas de dicho estudio fueron, entre otras, la valoración del programa por parte del profesorado como un buen elemento de apoyo a la docencia, eficaz en la tutorización virtual y con un interfaz sencillo y de fácil manejo. En lo que respecta a los estudiantes, su opinión también fue positiva, al considerarla una herramienta de fácil acceso y gran utilidad para la enseñanza.

\subsection{Evaluación de la herramienta entre el profesorado}

Para la realización de este trabajo se ha efectuado una encuesta entre los profesores que tienen asignaturas en el Grado de Periodismo en UDIMA para determinar cuál es su grado de satisfacción del uso de Elluminate Live! con los alumnos. En la encuesta participaron un total de 15 docentes que forman el conjunto de profesores que imparten clase en dicho grado durante el pasado curso académico 2010-2011. De ellos, 11 son mujeres y 4 son hombres, con una media de edad comprendida entre los 30 y los 45 años. La encuesta se confeccionó a través de la herramienta Google Docs, y

\footnotetext{
2 Sancerni Beitia, M. D. \& Villar Hernández, P. (2008. Evaluación de la plataforma Elluminate Live!: un estudio piloto en la Universitat de Valéncia. Revista d'innovació educativa. (1):. 63-72
} 
rue enviaaa por correo eiectronico a caaa uno ae ios encuestaaos.

Las respuestas recogidas de forma totalmente anónima corresponden a las diez preguntas planteadas en la encuesta. La temática de las cuestiones que se abordaron fueron muy diversas, desde la facilidad en el manejo de la herramienta y la dificultad a la hora de programar las clases, así como el grado de satisfacción en el uso del chat, la posibilidad de grabar las sesiones o la función de compartir escritorio, entre otras.

Los resultados de dicha encuesta se reflejan en el cuadro que se muestra a continuación. Conviene aclarar que las preguntas se plantearon en formato test, empleando una escala de 1 al 5 para cada respuesta, en donde 1 se corresponde con los valores "Muy en desacuerdo", "Muy inútil" o "Muy negativa"; mientras 5 se corresponde con los valores “Muy de acuerdo", “Muy útil” y “Muy positiva”.

Tabla1. Resultados de la encuesta realizada sobre Elluminate Live! en el Grado en Periodismo UDIMA.

Preguntas de la encuesta

Media de las respuestas obtenidas

1. Es una herramienta fácil de usar, se requiere poca 3 experiencia.

2. Es adecuada como un complemento a la enseñanza a 5 distancia.

3. Las sesiones resultan sencillas de programar.

4. Crees que aumenta la colaboración y comunicación 5 entre los estudiantes.

5. Cómo valoras el grado de utilidad de la pizarra y la presentación de diapositivas.

6. Cómo valoras la función de poder compartir escritorio.

7. Cómo valoras el uso del chat. 5

8. Cómo valoras la posibilidad de hablar varios usuarios a la vez.
9. Cómo valoras la posibilidad de grabar las sesiones. 5
10. Qué valoración general le darías a esta herramienta.
4 y 5

El valor más bajo se ha obtenido de la pregunta: "Es una herramienta fácil de usar, se requiere poca experiencia", donde el resultado obtenido ha sido de 3. Debemos tener en cuenta a este respecto que la incorporación de las TICs al mundo académico se ha realizado en un espacio de tiempo muy corto, por lo que resulta lógico pensar que muchos profesores se sientan inexpertos e inseguros ante el manejo de este tipo de herramientas en su labor cotidiana. Algunos, incluso, se muestran reacios ante el uso de las mismas. 
A la pregunta es adecuaaa como un compiemento a ra ensenanza a aistancia, eı resultado ha sido de $5(80 \%)$, seguido de $4(20 \%)$, lo que confirma la importancia del uso de la plataforma sobre todo en la educación a distancia $\mathrm{y}$, especialmente, en el ámbito universitario. Elluminate Live! es muy útil para la realización de tutorías virtuales, resolución de casos prácticos o defensa de los trabajos de fin de grado, entre otros.

El resultado a la pregunta "Las sesiones resultan sencillas de programar" fue de 4, un punto por encima de la respuesta obtenida a la cuestión "Es una herramienta fácil de usar, se requiere poca experiencia". De hecho, una vez que se realizan por vez primera, las sesiones posteriores resultan bastantes sencillas de programar, tan solo es necesario seguir una serie de pasos para la creación de la sesión. Con la última versión es posible programar varias sesiones a la vez en días y horas diferentes. Además, Elluminate Live! se puede utilizar desde un PC, un Mac o con Linux.

Un $40 \%$ de los profesores encuestados se encuentra "de acuerdo" y otro 40\% está "muy de acuerdo" en que la herramienta objeto de estudio aumenta la comunicación y la colaboración entre los estudiantes, así como entre el estudiante y el docente. El hecho de que varios alumnos se encuentren conectados entre sí en el mismo tiempo, fomenta la participación entre ellos, favorece que unos puedan colaborar con otros y, en definitiva, el proceso de aprendizaje resulta mucho más enriquecedor.

Si examinamos con detalle la valoración en el uso de las diferentes opciones que nos ofrece una sala de Elluminate Live! cuando estamos impartiendo clase (como es el uso de la pizarra virtual, el chat, la posibilidad de compartir escritorio, etc.), la encuesta nos revela cómo la opción más valorada de todas es la posibilidad de grabar las sesiones (80\%); seguido por el uso del chat (a un 60\% de los encuestados le resulta muy útil); la posibilidad de hablar varios usuarios a la vez (53\%); el uso de la pizarra virtual y la posibilidad de cargar presentaciones $(47 \%) \mathrm{y}$, entre lo menos valorado, la función de poder compartir escritorio (40\%).

La opción de grabar las sesiones resulta, sin duda, la más interesante de todas, ya que permite que aquellos alumnos que no hayan podido asistir a la clase por el motivo que sea, bien profesional o bien personal, accedan a la grabación y puedan realizar el visionado de la misma las veces que lo deseen. Esto resulta especialmente útil cuando las sesiones de Elluminate Live! se dedican para repasar lo fundamental de la materia de cara a la preparación del examen final de la asignatura. Además, es posible subir la grabación de las sesiones al canal que la UDIMA posee en You Tube.

Uno de los requisitos necesarios para poder asistir a una clase impartida a través de Elluminate es el uso de los auriculares y el micrófono. Los primeros resultan imprescindibles para poder escuchar las explicaciones del docente. En el caso del micrófono, su uso es obligatorio si se desea intervenir durante la lección, bien para realizar una pregunta o bien para aportar algún comentario añadido a lo explicado. Como no todos los asistentes tienen porque poseer un micro, el uso de un chat resulta muy interesante. El alumno aporta sus opiniones o responde a las preguntas 
pianteaaas a traves aeı cnat ae rorma comoaa $y$, a su vez, eı aocente visualiza comentarios aportados de forma muy rápida. De ahí que al 60\% de los profesores encuestados les resulte muy útil el uso del chat.

Con un $53 \%$ ha sido valorado en la encuesta la posibilidad de hablar varios usuarios a la vez. La plataforma, en estos momentos, está desarrollada para que puedan hablar hasta un máximo de seis hablantes a la vez. Esto en un principio nos puede resultar escaso, sobre todo, si pensamos en las sesiones a las que acude un número elevado de personas. Sin embargo, debemos pensar que realizar una clase virtual con más hablantes podría resultar dificultoso de llevar a cabo.

Tanto la pizarra virtual como la posibilidad de compartir escritorio resultan de gran utilidad para la enseñanza a distancia, a pesar de ser las menos valoradas, con un $47 \%$ y $40 \%$, respectivamente. Mediante la pizarra virtual es posible la presentación de diapositivas, textos, etc., así como imágenes sobre las que es posible dibujar o escribir encima, para señalarle al alumno algo en concreto que nos interese destacar. Con la opción de compartir escritorio, el docente puede mostrarles a los asistentes cualquier archivo o documento que se encuentre en su ordenador.

De los resultados obtenidos en la encuesta se evidencia que los docentes se encuentran en líneas generales satisfechos con el uso de la herramienta Elluminate, ya que la mayoría de las puntuaciones obtenidas oscilan entre el 4 y el 5 que se corresponden con los valores más altos de la escala.

\subsection{Evaluación de la herramienta entre los estudiantes}

A pesar de llevar tan sólo dos años de experiencia, han sido muchas las actividades docentes que se han realizado empleando para ello la herramienta de Elluminate Live! en las distintas materias que forman el Grado en Periodismo de la UDIMA. Por añadir algunos ejemplos, en la asignatura de Lengua Española de primer curso, mediante el uso de la pizarra virtual, los estudiantes deben realizar el análisis sintáctico de las distintas oraciones propuestas por el profesor, y éste a su vez, va realizando en la pizarra las correcciones que estima oportunas.

Del mismo modo, en la asignatura de Periodismo Escrito de segundo curso, más conocida como Redacción periodística, ya que los estudiantes aprenden a redactar los géneros informativos e interpretativos, las clases a través de Elluminate resultan muy interesantes ya que el docente explica a los asistentes mediante ejemplos que presenta en diapositivas las normas básicas de redacción de textos periodísticos y facilita al alumno que pueda escribir en la pizarra sus propios textos, entradillas o titulares. En Documentación Informativa, también de segundo, los alumnos extraen las diferentes clases de descriptores de un texto que les muestra el profesor.

En la asignatura de Comunicación Visual de primer curso, los estudiantes aprenden gracias a Elluminate cómo leer e interpretar las imágenes correctamente. De igual modo, el docente carga en la pizarra una presentación de diapositivas con las 
imagenes a anaiızar $\mathrm{y}$, sobre estas, tanto eı proresor como el aıumno (siempre y cuando éste reciba los permisos de edición por parte del profesor), pueden señalar, marcar, subrayar o escribir sobre las imágenes todo aquello que sea necesario para que los estudiantes entiendan bien los conceptos que deben aprender.

Los alumnos de UDIMA reciben al finalizar cada cuatrimestre una encuesta donde se les pregunta su opinión acerca de la utilidad de las diferentes herramientas que emplean a lo largo del curso académico. Si analizamos la última encuesta realizada por los alumnos del Grado en Periodismo, correspondiente al primer semestre del curso académico 2010-2011, vemos cómo el grado de satisfacción sobre el uso de Elluminate Live! fue de 4,20, eso si tenemos en cuenta que la escala era de 1 a 5, donde 1 equivale a "nada satisfecho" o "en total desacuerdo" y 5 a "totalmente satisfecho" o "totalmente de acuerdo".

Si comparamos esta calificación con el resto de valores obtenidos en la encuesta de las herramientas que componen el aula virtual de cada asignatura, lo más valorado son los buzones de entrega de ficheros $(4,70)$; los cuestionarios de preguntas y respuestas múltiples $(4,66)$; los foros $(4,48)$; los directorios de material didáctico complementario $(4,39)$ y las consultas $(4,36)$. Por debajo de la calificación obtenida en Elluminate, los alumnos han valorado don un 3,72 los glosarios; con 3,58 la herramienta Google Docs; con un 3,50 las audioconferencias telefónicas; con un 3,02 las salas de chat y, únicamente con 2,67, la plataforma Second Life.

Al igual que en el caso de los docentes, el grado de satisfacción de los estudiantes de Periodismo de la UDIMA respecto a la utilización de Elluminate Live! como complemento a las clases es muy alto, especialmente si lo comparamos con otras herramientas que sirven también de apoyo a la docencia, como es Google Docs o Second Life. El estudio llevado a cabo confirma que Elluminate es un instrumento imprescindible en la enseñanza de la educación a distancia universitaria, por lo que es altamente su recomendación durante el desarrollo de la misma. Además que se encuadra en el EEES, en el que el alumno juega un papel fundamental en este nuevo planteamiento de enseñanza.

\section{CONCLUSIONES}

Las TICs han modificado los modos de interacción entre el profesor y sus estudiantes, la cual puede tener lugar tanto de forma sincrónica como asincrónica. Esto favorece e incrementa los flujos de información y la colaboración entre ellos más allá de los límites físicos de la universidad a la que pertenecen. Sus rasgos más característicos están relacionados con la inmaterialidad, interactividad, instantaneidad, innovación y digitalización, entre otros.

La enseñanza del periodismo abarca el estudio de materias muy prácticas, lo que implica que los contenidos teóricos se complementen con los supuestos prácticos para que el alumno pueda plasmar la teoría aprendida al caso concreto dado por el profesor. Pensando en una enseñanza a distancia, con frecuencia es necesario 
interreıacionar con eı aıumno en tiempo reaı, con to que resulta mas erectivo eı uso de herramientas sincrónicas para responder a las dudas planteadas por los alumnos que si el profesor lo explica a todos sus estudiantes de manera individualizada.

En ese sentido, Elluminate Live! es una plataforma a través de la cual el alumno puede tener la sensación de que se encuentra en una clase presencial, ya que tiene lugar una interacción entre los estudiantes y el docente. De este modo, las tutorías on-line constituyen uno de los principales usos que se le puede atribuir a esta herramienta, sin olvidar la facilidad que se les otorga a los alumnos para elaborar trabajos en grupo, exponer sus trabajos o incluso realizar exámenes orales a través de la webcam.

Para una mayor eficacia en el uso de las TICs, las universidades deben formar a sus docentes de una manera adecuada. A este respecto debemos añadir que Elluminate destaca por su fácil manejo. En conjunto es una herramienta de uso sencillo para la que no se requiere experiencia previa. El docente, una vez que aprende los pasos a seguir para poder programar sus sesiones, resulta un proceso repetitivo de lo más sencillo. El alumno por su parte tan solo necesita de una conexión a Internet y puede entrar en la sesión desde cualquier parte del mundo.

Podríamos enumerar más ventajas en la utilización de esta herramienta, como por ejemplo, que permite grabar las sesiones, de tal modo que todos aquellos estudiantes que no han podido asistir a la clase, siempre pueden disponer de la grabación para su visualización en cualquier momento. Sin embargo, tampoco podemos olvidar que de la misma se deriva una gran desventaja, y no es otra que la "picardía" del alumno para engañar al profesor haciéndole creer que se encuentra presente en la sesión cuando en realidad no lo está. El mejor modo que evitar esto es que el docente haga participativa su clase, realizando preguntas con cierta frecuencia a los asistentes y que estos responden a las cuestiones planteadas bien por el chat o bien mediante los icónicos de respuesta con los que cuenta la herramienta.

En definitiva, entre las principales características que ofrece el uso de las nuevas herramientas educativas, tal vez la más interesante sea que el estudiante se vuelve "responsable" de su propio aprendizaje, es decir, el aprendizaje se basa en un sistema de evaluación continua basado en una supervisión personalizada por parte del docente del trabajo que realiza el alumno, de ahí que podamos afirmar que éste es en cierto modo el responsable de su propia evolución.

\section{REFERENCIAS}

Cabero, J.(1996). Nuevas tecnologías, comunicación y educación. Revista electrónica de Tecnología Educativa, (1). Consultado el 30 de Agosto de 2011, de: http://www.uib.es/depart/gte/revelec1.html

Casals Carro, M. .J. (2006). La enseñanza del periodismo y las nuevas tecnologías de la información y de la comunicación. Estudios sobre el Mensaje Periodístico, (12). Consultado el 5 de Septiembre de 2011, de: 
Castells, M. (1997). La era de la información. Economía. Sociedad y Cultura. Madrid: Alianza Editorial.

Castillo Arredondo, S. \& Cabrerizo Diago, J. (2006). Formación del profesorado en educación superior. Desarrollo curricular y Evaluación. Madrid: Mc Graw-Hill.

Ferro Soto, C.; Martínez Senra, A. I. \& Otero Neira, M. del C. (2009). Ventajas del uso de las TICs en el proceso de enseñanza-aprendizaje desde la óptica de los docentes universitarios españoles. Revista Electrónica de Tecnología Educativa. (29). Consultado el 5 de Agosto de 2011, de:

http://www.colombiadigital.net/newcd/component/docman/doc_details/1192

Marqués, P. (2001). Algunas notas sobre el impacto de las TIC en la universidad. Educcar, 28.

Ortega y Gasset, J. (1982). Misión de la Universidad y otros ensayos sobre educación y pedagogía. Madrid: Alianza Editorial.

Palacio, Gorka J. (2010). Sistemas con contenido audiovisual y multimedia para el desarrollo de entornos de e-learning 2.0. En Landeta, A. (coord.). Nuevas tendencias de elearning y actividades didácticas innovadoras. Madrid: CEF..

Rosario, J.(2005). La tecnología de la Información y la Comunicación. Su uso como herramienta para el fortalecimiento y el desarrollo de la educación virtual. Consultado el 5 de Septiembre de 2011, Disponible en el archivo del Observatorio para la CiberSociedad de: $\underline{\text { http://www.cibersociedad.net/archivo/articulo.php?art=218 }}$

Salinas, J. (1997). Nuevos ambientes de aprendizaje para una sociedad de la información" en Revista Pensamiento Educativo. (20).

\section{Ana Virginia Rubio-Jordán}

Profesora titular adjunta en el Grado en Periodismo de la Universidad a Distancia de Madrid (UDIMA). Licenciada en Periodismo por la Universidad Complutense de Madrid (UCM). Doctora en Ciencias de la Información por la UCM. Máster en Periodismo de Agencia por la Universidad Rey Juan Carlos. Ha impartido docencia en la Universidad Camilo José Cela y ha desarrollado labores periodísticas principalmente en la Agencia Efe entre otros medios de comunicación. Sus líneas de investigación son la gestión de empresas informativas (sobre todo la prensa gratuita en nuestro país) y el estudio de herramientas de innovación docente aplicadas a la enseñanza a distancia. 